https://helda.helsinki.fi

\title{
Social demands and resources predict job burnout and engagement profiles among Finnish employees
}

\section{Upadyaya, Katja}

2020-07-03

Upadyaya , K \& Salmela-Aro, K 2020 , ' Social demands and resources predict job burnout and engagement profiles among Finnish employees ' , Anxiety, Stress and Coping , vol. 33 , no. 4 , pp. 403-415 . https://doi.org/10.1080/10615806.2020.1746285

http://hdl.handle.net/10138/328480

https://doi.org/10.1080/10615806.2020.1746285

unspecified

acceptedVersion

Downloaded from Helda, University of Helsinki institutional repository.

This is an electronic reprint of the original article.

This reprint may differ from the original in pagination and typographic detail.

Please cite the original version. 
Running head: JOB BURNOUT AND ENGAGEMENT PROFILES

Social Demands and Resources Predict Job Burnout and Engagement Profiles among Finnish Employees 


\begin{abstract}
Background and Objectives: Latent profiles of employees' job burnout (e.g., exhaustion, cynicism, feelings of inadequacy) and work engagement (e.g., energy, dedication, absorption) were examined. Moreover, the role of social work-related (multicultural, interpersonal, and project work demands) and personal demands (relationship demands) and social work-related resources (servant leadership, team climate) and personal resources (resilience, self-efficacy) in predicting the latent profiles were examined.

Design: This study is a part of an Occupational Health Study in which 766 employees participated twice.

Methods: The results were analyzed using latent profile analysis.

Results: Two longitudinal profiles of burnout and engagement could be identified, namely high engagement (84\% of the participants) and increasing burnout (16\%) profiles. Employees who experienced high work-related social resources (servant leadership) and high personal resources (resilience, self-efficacy) were more likely to belong to the high engagement group than to the increasing burnout group. Employees who experienced high work-related social demands (multicultural, interpersonal, and project work demands) and personal social demands (relationship demands) more often belonged to the increasing burnout group.

Conclusions: Social resources may help in promoting employees' job engagement, whereas social demands are often associated with increasing burnout symptoms.
\end{abstract}

Keywords: Job burnout, work engagement, latent profiles, work demands and resources 


\section{Social Demands and Resources Predict Job Burnout and Engagement Profiles among Finnish Employees}

Job burnout and engagement represent two core concepts in occupational health psychology and in the job demands-resources theory, describing two different sides of workrelated well-being, one (e.g., burnout) leading to poor health and decreases in job performance, and the other (e.g., engagement) leading to increased well-being and positive organizational outcomes (Bakker, Demerouti, \& Sanz-Vergel, 2014). The associations between job burnout and engagement have mainly been examined at the variable-level, often indicating negative correlations varying from -.20 to -.90 between the two constructs (Mäkikangas, Feldt, Kinnunen, \& Tolvanen, 2012; Mäkikangas \& Kinnunen, 2016; Schaufeli, Taris, \& van Rhenen, 2008). However, these variations in the correlations challenge the idea that the associations between job burnout and engagement would be similar to all employees and instead suggest that different employees can experience different levels of job burnout and engagement simultaneously (Mäkikangas \& Kinnunen, 2016; Timms, Brough, \& Graham, 2012). These differences can be captured by person-oriented approach which focuses on individuals rather than variables (von Eye, Bergman, \& Hsieh, 2015). Person-oriented approach provides researchers a tool to identify various subpopulations of employees reflecting similar underlying characteristics of job-related well-being (Woo, Jebb, Tay, \& Parrigon, 2018). On the basis of clustering, latent profile analyses identifies homogeneous groups of employees that share common patterns according to the variables of interest (see also Hu, Schaufeli, \& Taris, 2017; Knisely \& Draucker, 2016). However, more studies would be needed investigating the longitudinal associations between job burnout and engagement using person-oriented approach (Mäkikangas, Kinnunen, Feldt, \& Schaufeli, 2016; Mäkikangas, Kinnunen, Rantanen, Mauno, Tolvanen, \& Bakker, 2014; 
Mäkikangas et al., 2012).). Consequently, the present study examines the latent profiles of job burnout (e.g., exhaustion, cynicism, and feelings of inadequacy at work) and engagement (e.g., energy, dedication, and absorption) across two time points among Finnish employees.

Additionally, the role of several work-related and personal social demands and resources in predicting employees' membership in the latent profiles is examined further.

\section{Work-Related Burnout and Engagement}

Job burnout is typically described as a prolonged reaction to chronic emotional and interpersonal stressors at work, whereas work engagement is characterized as a positive, fulfilling, work-focused mental state (González-Romá, Schaufeli, Bakker, \& Lloret, 2006; Salmela-Aro, Kiuru, Leskinen, \& Nurmi, 2009; Schaufeli, Salanova, Gonzáles-Roma, \& Bakker, 2002).

Job burnout is characterized by three dimensions, namely exhaustion, cynicism, and feelings of inadequacy at work (Gonzáles-Roma et al., 2006; Näätänen et al., 2003; Salmela-Aro, Näätänen, \& Nurmi, 2004; Schaufeli et al., 2002). Exhaustion is characterized by strain and overtaxing from work; cynicism is described by loss of interest and distal attitude toward work, and not seeing work as meaningful; and feelings of inadequacy are often characterized by feelings of incompetence as an employee (Salmela-Aro et al., 2009; Schaufeli et al., 2002). The research using the UWES-9 to measure work engagement focuses on three dimensions of engagement, i.e., energy, dedication, and absorption at work (Schaufeli et al., 2002). Energy is described by high vigor and mental resilience while working, and persistence even while facing difficulties; dedication describes a sense of high significance, and being enthusiastic and inspired by one's work, as well as taking pride in one's work; absorption is characterized by 
being fully concentrated and happily engrossed in one's work, so that time passes quickly and it may be difficult to detach from work (Schaufeli et al., 2002).

Research focusing on the mean level development of job burnout and engagement has not been able to capture individual differences in burnout and engagement (Innanen, Tolvanen, \& Salmela-Aro, 2014). These differences can be captured by person-oriented approach which seeks to identify various subpopulations of employees reflecting similar underlying traits or characteristics (e.g., job burnout and engagement) (Woo et al., 2018). Based on previous personoriented research it is clear that burnout symptoms do not manifest nor develop in a similar manner among all individuals (Mäkikangas et al., 2016). For example, longitudinal personoriented research on employees' exhaustion (e.g., burnout dimension) and vigor (e.g., engagement dimension) has been able to identify low stable exhaustion, high stable vigor ( $84 \%$ of the participants), fluctuating exhaustion and vigor (11\%), and stable average exhaustion, decreasing vigor (5\%) subgroups of employees (Mäkikangas, Hyvönen, Feldt, 2017; see also Mäkikangas et al., 2014 for short term longitudinal development ). Cross-sectional personoriented research, in turn, has been able to identify subgroups of employees whose level of engagement and burnout vary from highly engaged (41.4\%) to highly burned out (1.8\%) groups (Moeller, Ivcevic, White, Menges, \& Brackett, 2018). However, despite of various studies examining the latent profiles of job burnout and engagement, the results of these studies vary greatly, partly speaking for the existing replication crisis in psychological science (Maxwell, Lau, \& Howard, 2015; Shrout \& Rodgers, 2018). Thus, more research would be needed to examine latent profiles of job burnout and engagement, and to investigate whether similar latent profiles emerge in different data sets, and help in determining the replicability of the existing research. In previous longitudinal studies, latent groups have been formed, for example, 
separately for each job burnout and engagement dimensions (Mäkikangas et al., 2012), separately for exhaustion and vigor, and for cynicism and dedication (Mäkikangas et al., 2017), including all job burnout and engagement dimensions in combination with workaholism (Innanen et al., 2014), and by examining job burnout dimensions and overall engagement (Salmela-Aro et al., 2019). Because these previous findings have indicated that both the level of job burnout dimensions and engagement dimensions typically vary across the latent classes and may or may not co-occur (Innanen et al., 2014; Mäkikangas et al., 2012; Mäkikangas et al., 2017), all dimensions of job burnout were examined in combination with all dimensions of work engagement in the present study.

\section{Job Demands and Resources}

The Job Demands-Resources (JD-R) Model (Bakker, Demerouti, De Boer, \& Schaufeli, 2003; Bakker \& Demerouti, 2006, 2017; Demerouti, Bakker, Nachreiner, \& Schaufeli, 2001) postulates that different personal- and work-related demands and resources antecede employees' job burnout and engagement which further manifest in employees' general and occupational health outcomes (de Jonge, Vegehel, Shimatzu, Schaufeli, \& Dormann, 2010; Upadyaya, Vartiainen, \& Salmela-Aro, 2016). Job demands are characterized by those aspects of work that require sustained physical/psychological effort and include related costs (Demerouti et al., 2001). Job demands are not necessarily negative, however, when one's effort required to meet them is high and when multiple demands are present simultaneously, they may turn into stressors (Bakker, Demerouti, \& Schaufeli, 2003). Job demands include, for example, workload, time pressure (Bakker et al., 2003), and project work (Pinto, Dawood, \& Pinto, 2014). Personal demands describe aspects of an individual's characteristics which are reflected in their effort at work, and associated with psychological and physical costs (see also Bakker \& Demerouti, 
2017). Personal demands may include long-term illness and family economic problems (Salmela-Aro \& Upadyaya, 2018). Job- and personal demands can also be related to the social aspect of the job/personal life, such as interpersonal conflict and demands related to multicultural work environments (e.g, language barriers, cultural differences) (see also Leiter \& Maslach, 2016; Pyhältö, Pietarinen, \& Salmela-Aro, 2011) and strain at home (Peeters, Montgomery, Bakker, \& Schaufeli, 2005). Social environment is of fundamental importance for employees' well-being, and interpersonal stressors are often among the most common stressors at work (Bruk-Lee \& Spector, 2006; Hahn, 2000). Workplaces are also becoming increasingly multicultural, including employees from more than one ethnicity, nationality, and religious or cultural groups (Pasca \& Wagner, 2012; Rozkwitalska \& Basinka, 2015). Multiculturality can make the work environment more enriching (Rozkwitalska \& Basinka, 2015), however, sometimes multicultural stressors at the workplace may negatively influence communication, sense of belonging, and employees' well-being (Pasca \& Wagner, 2011). Also project work is often social by nature, involving teams who have to face deadlines and budgetary restrictions, report to stakeholders, and respond quickly to changing situations, which makes project work often fast-paced, highly demanding, and stressful (Pinto et al., 2014). These demands related to work projects are often reflected in employee burnout symptoms (see also Pinto et al., 2014).

Job resources describe different physical, psychological, social or organizational aspects of job that either/or: (1) reduce job demands and their physiological and psychological costs; (2) are functional in aspiring work-related goals; and (3) stimulate personal growth, development, and learning (Demerouti et al., 2001; Demerouti, \& Bakker, 2011). Job resources include job characteristics such as autonomy, social support, team climate and servant leadership which help in reducing burnout symptoms and promote job engagement (Bakker \& Demerouti, 2007; 
Bakker et al., 2003; Salmela-Aro \& Upadyaya, 2018; Upadyaya et al., 2016). For example, servant leadership characterized by stewardship, empowerment, and accountability (Russell \& Stone, 2002) is positively associated with job satisfaction (Cerit, 2009) and organizational trust (Joseph \& Winston, 2005), and decreases in employees' burnout symptoms (Babakus, Yavas, \& Ashill, 2011). Social support from colleagues and supervisors is an important job resource which may further manifest as high employee engagement (Bakker et al., 2007) and work intrinsic motivation (Van Yperen \& Hagedoorn 2003). Thus, the present study focused on examining two distinct social job resources: servant leadership (supervisor's support) and team climate (colleagues' support), and their associations with employees' burnout and engagement profiles.

Personal resources, in turn, include self-efficacy, resilience, and optimism which have a direct positive impact on work engagement (Bakker \& Demerouti, 2008, 2017; Xanthopoulou et al., 2009). Personal- and work resources may also buffer against the negative influence of job demands (e.g., pupil misbehavior, workload) on work engagement (Bakker, Hakanen, Demerouti, \& Xanthopoulou, 2007; Upadyaya et al., 2016). However, besides buffering against job demands, resources are also important in their own right. For example, lack of resources may lead to decreased work engagement and increases in burnout symptoms (Hakanen, Bakker, \& Schaufeli, 2006). In the present study the associations between resilience (e.g., the ability to bounce back after facing difficulties) and work-related self-efficacy with employees' job burnout and engagement profiles were examined further.

\section{The Present Study}

The present study addressed two main questions. (1) What kind of latent homogeneous groups of employees can be identified according to the level and changes in their exhaustion, cynicism, and feelings of inadequacy (e.g., burnout) and energy, dedication, and absorption (e.g., 
engagement) at work? Based on the findings of some recent studies (Innanen et al., 2014; Salmela-Aro, Hietajärvi, \& Lonka, 2019) we expected to find at least two latent profile groups, one characterized by a high level of work engagement and lower levels of burnout, and another characterized by high levels of burnout symptoms and lower level of work engagement. Second, after identifying the latent profile groups, we sought to explore (2) to what extent several social work-related (e.g., multicultural, interpersonal, and project work demands) and personal demands (e.g., relationship demands) and social work-related (e.g., servant leadership, team climate) and personal resources (e.g., resilience, self-efficacy) predict employees' belonging to the latent job burnout and engagement profiles? Based on the JD-R theory (Bakker \& Demerouti, 2017), we expected that work-related and personal social demands, in particular, would predict employees belonging to the high burnout group, and work-related social resources and personal resources, in particular, would predict employees belonging to the high engagement group.

\section{Method}

This study is a part of the Occupational Health Study in which 766 employees (396 men, 370 women) were followed twice (spring 2011 and 2012). The participants filled in an e-mail questionnaire concerning their burnout symptoms, work engagement, perceptions of demands and resources, and occupational health. Participation in the study was voluntary and confidential, as was explained in the cover letter of the questionnaire. The study followed the Declaration of Helsinki ethical principles. The average age of the participants was 44 (range 20-64; 22\% were 20-35 years old; $30 \%$ were $36-45 ; 38 \%$ were $46-55,19 \%$ were $56-65$ ). Three organizations (a multinational network service provider, a public sector's administration official, and a global water chemistry company) were chosen to the study by their large size (employing over 500 people) and by their occupational health service provider, through which the data were collected. 
The response rate varied between $34 \%$ and $39 \%$. The educational distribution was university degree (44\%), polytechnic degree (37\%), vocational degree (9\%), compulsory education (5\%), and double degree (3\%), and occupational role was workers in customer services $(19 \%)$, specialists (64\%), immediate supervisors $(7 \%)$, middle management $(8 \%)$, and corporate management $(2 \%)$.

\section{Measures}

Job burnout (Times 1 and 2) was measured with the Bergen Burnout Inventory (Näätänen, Aro, Matthiensen, \& Salmela-Aro, 2003; see Salmela-Aro, Rantanen, Hyvönen, Tilleman, \& Feldt, 2011 for validity) which consists of 15 items measuring (1) exhaustion at work ( e.g., 'I feel overwhelmed by my work') (Cronbach's $\alpha=.81 / .79)$; (2) cynicism about the meaning of work (e.g., 'I feel lack of motivation in my work and often think of giving up') $(\alpha=.84 / .86)$; and (3) sense of inadequacy (e.g., 'I often have feelings of inadequacy in my work') $(\alpha=.78 / .78)$ to be rated on a 6 -point scale $(1=$ strongly disagree; $6=$ strongly agree $)$.

Work Engagement (Times 1 and 2) was measured with a short version of the Utrecht Work Engagement Scale, UWES-9 (Schaufeli et al., 2002, see also Schaufeli et al., 2006). The scale consists of 9 items measuring energy (e.g., 'When I work, I feel that I am bursting with energy') ( $\alpha=.91 / .92)$, dedication (e.g., 'I am enthusiastic about my work') $(\alpha=.93 / .93)$, and absorption (e.g., 'Time flies when I'm working') $(\alpha=.82 / .88)$ at work. Energy, dedication, and absorption are similar to emotional, cognitive, and behavioral aspects of engagement (SalmelaAro \& Upadyaya, 2014; Upadyaya \& Salmela-Aro, 2013). The responses were rated on a 7-point scale $(0=$ not at all; $6=$ daily $)$.

Work Demands. Questions concerning work demands and resources were developed in collaboration with our research team and the occupational health service psychologists. 
Employees' experiences of work-related social demands were measured with three questions concerning multiculturality work demands (presented after the leading question [At your work, do you experience confusion, disturbances, and interferences related to multiculturality?] 'How demanding are the confusions, disturbances, and interferences caused by multiculturality at your work?'), interpersonal work demands ('How demanding are the interpersonal relationships related to your work?'), and project work demands ('How demanding you find the practices related to starting new projects at work?'). The answers were rated $0=$ not at all; $7=$ extremely demanding.

Personal Demands. Employees' personal demands (Time 1) were measured in terms of relationship demands. Employees rated whether they had experienced relationship demands during the recent years ("[Have you experienced some of the following life events during the recent years? To what extent they still affect you?] Breakage of an important personal relationship.'). The answers were rated $0=\mathrm{I}$ haven't experienced this life event; $4=\mathrm{I}$ have experienced/I am currently experiencing this life event and it affects me to a great extent.

Work Resources (Time 1) concerned team climate ('To what extent do relationships between employees function as a resource for you?', 1 item; $0=$ not at all to $7=$ to great extent) and servant leadership ('My manager helps me to further develop myself', 16 items $(\alpha=.90) ; 1=$ totally disagree, 5=totally agree; Van Dierendonck \& Nuijten, 2011).

Personal Resources. Employees' personal resources were measured with questions concerning work-related self-efficacy beliefs (8 items; Scholz, Doña, Sud, \& Schwarzer, 2002) ( 'If I come up against difficulties at work, I usually figure out a way'; 1 = totally disagree; 5 = totally agree; $\alpha=.86$ ) and resilience ('I recover quickly from difficult situations.'; 6 items; $1=$ totally agree; $5=$ totally disagree; $\alpha=.87$; Smith et al., 2008). 


\section{Analysis Strategy}

The results were analyzed by means of latent profile analysis (LPA; Muthén \& Muthén, 1998-2020), which is a type of finite mixture analysis that assesses heterogeneity through the identification of homogeneous subgroups (i.e. latent profiles) of participants with similar indicator means (e.g., job burnout and engagement) within the latent profiles. The LPAs were carried out in two phases. First, LPAs for different latent groups were carried out, and the fit indices and class frequencies were compared. The variances were estimated equal between the classes. The estimation was performed step by step, starting from one-class solution to estimate the parameters for $2,3, \ldots, k$-class solutions. The solution that best fitted the data in accordance with the indicators and that was also deemed reasonable in terms of interpretation was chosen as the final latent profile model. Second, in order to identify the possible antecedents of the latent profiles, different work-related (e.g., multicultural, interpersonal, and project work demands) and personal social demands (e.g., relationship demands), and work-related social resources (e.g., servant leadership, team climate) and personal resources (e.g., resilience, self-efficacy) were added into the final mixture model as covariates using the manual 3-step procedure (Asparouhov \& Muthén, 2014). In the 3-step procedure, after determining the number of latent profiles (step 1, as described above), the profile probabilities were saved in a new data set with the covariates (step 2), and using the new data set the role of the antecedents was examined further (step 3; see Asparouhov \& Muthén, 2014). The benefit of the 3-step procedure is that the forming of the latent profiles is free from the effect of the covariates. Each covariate was added in the model separately (see Table 1 for means, standard deviations, and correlations).

[Table 1 near here] 
All the analyses were performed with the Mplus statistical package (version 8; Muthén \& Muthén, 1998-2020). Missing data was deleted listwise, which was the default for this type of analysis (Muthén \& Muthén, 1998-2020). Because the variables were skewed, we estimated the model parameters by means of maximum likelihood robust (MLR) estimator, which is robust to the non-normality of the observed variables. MLR produces standard errors and a chi-square test statistic for missing data with non-normal outcomes by means of a sandwich estimator and the Yuan-Bentler T2 test statistic (Muthén \& Muthén, 1998-2020).

\section{Results}

Five criteria were used to decide the final number of classes: (a) the Bayesian information criterion (BIC), and (b) the Akaike information criterion (AIC), according to which the model with the smallest value is considered the best model; (c) the Vuong-Lo-Mendell-Rubin (VLMR) test of fit, which compares solutions with different numbers of classes (a low $p$ value indicates that the $k$ model has to be rejected in favor of a model with at leat $k+1$ classes); (d) entropy values, which determine classification quality (values close to 1 indicate clear classification) (Celeux \& Soromenho, 1996); and (e) the clarity and interpretation of the classes.

Comparison of the fit indices (Table 2) and class frequencies showed that when a third group was included in the analyses, the entropy slightly increased, however, the VLMR test did not support the inclusion of the third group, to which only $3 \%$ of the employees belonged. Thus, because the two-class solution was theoretically meaningful and the goodness-of-fit indices indicated that the second latent group was necessary, the two-latent-group solution was considered the best model. The final two-group solution is presented in Figure 1.

[Table 2 near here]

[Figure 1 near here] 
The first latent group (84\%) was characterized by an average level of exhaustion, cynicism, and feelings of inadequacy at work, and an initially high energy, dedication, and absorption at work which slightly increased over time ${ }^{1}$. The second latent group (16\%) was characterized by a relatively high level of exhaustion, cynicism, and feelings of inadequacy at work, which also increased across time, and an average level of energy, dedication, and absorption at work which slightly decreased over time. The latent groups were labeled as high engagement and increasing burnout groups.

The results for the covariates showed that employees who experienced high work-related social resources (e.g., servant leadership) and personal resources (e.g., resilience, self-efficacy) were more likely to belong to the high engagement group than to the increasing burnout group (Table 3). Moreover, employees who experienced high work-related (e.g., multicultural, interpersonal, and project work demands) and personal social demands (e.g., relationship demands) more often belonged to the increasing burnout group than the high engagement group.

[Table 3 near here]

\section{Discussion}

This study examined the latent profiles of employees' job burnout and work engagement in a longitudinal design across two measurement points. The results showed that two distinct latent profile groups could be identified: a majority (84\%) of employees belonged to a high engagement latent profile group, and a small number (16\%) of employees belonged to an increasing burnout latent profile. Employees who experienced high work-related social resources more often belonged to the high engagement group, whereas employees who experienced high work-related and personal social demands more often belonged to the increasing burnout group.

\footnotetext{
${ }^{1}$ See supplementary material for Wald tests examining the differences between these variables.
} 


\section{Latent Job Burnout and Engagement Profiles}

The present results showed also that employees who belonged to the high engagement profile (84\%) simultaneously experienced an average level of burnout symptoms, whereas among employees who belonged to the increasing burnout profile (16\%) the initially relatively high level of exhaustion, cynicism, and feelings of inadequacy also increased across time, and energy, dedication, and absorption slightly decreased over time. It is possible that some employees simultaneously experience high vigor and exhaustion at work (Mäkikangas et al., 2012; Mäkikangas et al., 2014), reflecting employees' prolonged high engagement and effort at work. However, among smaller number of employees burnout symptoms became increasingly elevated over time, which may become a risk for their subsequent work-related well-being. In the increasing burnout profile employees' feelings of absorption were slightly higher and energy lower than the two other work engagement dimensions. It is possible that some employees in the increasing burnout group suffered from workaholism, and despite feeling high absorption (e.g., behavioral engagement) at work suffered from lowered energy (e.g., emotional engagement) as a result of job strain (Bakker \& Demerouti, 2017; see also van Beek, Taris, \& Schaufeli, 2011).

\section{Personal- and Job Demands and Resources}

Employees who experienced high work-related social resources (e.g., servant leadership) and high personal resources (e.g., resilience, self-efficacy) were more likely to belong to the high engagement group than to the increasing burnout group. High social resources at work, especially related to supportive leadership styles, such as servant leadership, may promote employees' high work engagement and protect against job burnout symptoms ( Upadyaya et al., 2016). However, no associations emerged between team climate (e.g., social support from colleagues) and the latent job burnout and engagement profiles. Team climate is closely 
associated with leadership style; for example, servant leadership often promotes employees' work-related self-efficacy and group identification (Chen, Zhu, \& Zhou, 2014). Thus, it is possible that servant leadership is a stronger social resource at work than team climate, which may explain why no associations emerged between team climate and job burnout and engagement profiles in the present study. Servant leaders often emphasize employees' growth and development to increase employees' capacities at work (Luthans \& Avolio, 2003), which may serve as great social resource at work, promoting high engagement and hindering job burnout among employees.

The results showed further that employees who reported experiencing high work-related social demands (e.g., multicultural, interpersonal, and project work demands) and personal social demands (e.g., relationship demands) more often belonged to the increasing burnout group than the high engagement group. Interpersonal demands may increase negative emotions and depressive symptoms among employees (Hahn, 2000), which may also show as increases in job burnout symptoms. Multicultural demands may manifest as communication problems and decreases in employees' sense of belonging (Pasca \& Wagner, 2011) and job satisfaction (Rozkwitalska \& Basinka, 2015), which, when prolonged, may elevate job burnout symptoms. Similarly, project work often includes some level of conflict and stress between the team members, which may further alter employees' burnout symptoms (see also Pinto et al., 2014). These results are also in line with the JD-R model ( Bakker \& Demerouti, 2006, 2017), and add to the existing literature by showing that also social resources and demands play an important role in employee's work-related well-being.

\section{Practical Implications and Suggestions for Future Research}


Modern work environments are increasingly multicultural which may cause various types of demands related to multiculturality and interpersonal factors to emerge among employees (e.g., problems in communication, difficulties in adjustment) and further manifest as decreases in employee well-being (Pasca \& Wagner, 2011) and job satisfaction (Rozkwitalska \& Basinka, 2015). Social resources at work (e.g., servant leadership), in turn, promote employees' engagement, and may protect against burnout symptoms. Through the job energy compass guidelines (Schaufeli, 2017), which helps in identifying workplace demands and resources, both employers and employees could recognize and improve workplace social resources (e.g., by supporting team members' adjustment to multicultural project teams) and decrease social demands (e.g., by applying new policies to prevent personnel turnover) (see also Rozkwitaska \& Basinska, 2015).

Moreover, social factors that might initially be experienced as demands (e.g., multiculturality) may manifest as social resources after employees' adjustment to the social environment and promote their well-being (see also Puck, Mohr, \& Rygl, 2008). In future studies longitudinal processes between social factors that might manifest as job demands or resources, and their associations with employees' adjustment, burnout, and engagement should be examined in further detail. Future studies should also assess the relative importance of different social demands and resources using methods such as dominance analysis. This would help researchers to determine the most important contributors to employees' job burnout and engagement (Hakanen, Ropponen, Schaufeli, \& De Witte, 2019). Training in social skills, open communication, and cultural sensitivity at the workplace may help employees to overcome different social demands related to multicultural and interpersonal stressors (see also Pasca \& Wagner, 2011; Puck et al., 2008) and to better adjust to the increasingly multicultural workplaces 
(Rozkwitaska \& Basinska, 2015). These are also skills that are needed more and more in the modern workplaces. Feeling valued and supported by one's supervisors and colleagues makes the work environment more pleasant and rewarding (Van Yperen \& Hagedoorn 2003).

\section{Limitations}

First, the response rate from the three organizations participating the study was relatively low, which may have influenced the obtained results. Second, other variables which were not examined in the study might have affected the results. For example, employees' educational level may influence the level of their burnout and engagement at work (Innanen et al., 2014). Third, the way the question concerning multicultural demands was presented might have led employees to emphasize their experiences of related demands more than was actually true. Future studies should develop measures which would take into account both the demands as well as resources related to multiculturality at the workplace (see also Rozkwitaska \& Basinska, 2015). Moreover, some variables were measured with only one item in the present study; it is possible that if more questions were included for these measures, some results would have turn different, and, for example, more results would have emerged between the engagement and burnout profiles and team climate at the workplace.

\section{Conclusions}

The present findings indicated that most employees experience a high level of work engagement combined with an average level of simultaneous burnout symptoms, which may also reflect employees' high interest, commitment, and effort in their work. The level of engagement also remains high among these employees. A smaller number of employees suffer from increasing burnout symptoms, to which different social demands at work and in personal life may contribute, as the findings of the present study showed. 


\section{References}

Asparouhov, T., \& Muthén, B. (2014). Auxiliary variables in mixture modeling: Three-step approaches using Mplus. Structural Equation Modeling: A Multidisciplinary Journal, 21(3), 329-341. doi: 10.1080/10705511.2014.915181

Babakus, E., Yavas, U., \& Ashill, N. J. (2010). Service worker burnout and turnover intentions: Roles of person-job fit, servant leadership, and customer orientation. Services Marketing Quarterly, 32(1), 17-31. doi: 10.1080/15332969.2011.533091

Bakker, A. B., Albrecht, S. L., \& Leiter, M. P. (2011). Work engagement: Further reflections on the state of play. European Journal of Work and Organizational Psychology, 20, 74-88. doi: 10.1080/1359432X.2010.546711

Bakker, A. B., \& Demerouti, E. (2006). The Job Demands-Resources model: state of art. Journal of Managerial Psychology, 22, 309-328. doi: 10.1108/02683940710733115

Bakker, A. B., \& Demerouti, E. (2007). The job demands-resources model: State of the art. Journal of Managerial Psychology, 22(3), 309-328. doi: 10.1108/02683940710733115

Bakker, A. B., \& Demerouti, E. (2017). Job demands-resources theory: Taking stock and looking forward. Journal of Occupational Health Psychology, 22, 273. doi: $10.1037 /$ ocp0000056

Bakker, A. B., \& Demerouti, E. (2008). Towards a model of work engagement. Career Development International, 13, 209-223. doi: 10.1108/13620430810870476

Bakker, A. B., Demerouti, E., De Boer, E., \& Schaufeli, W. B. (2003). Job demands and job resources as predictors of absence duration and frequency. Journal of Vocational Behavior, 62(2), 341-356. doi: 10.1016/S0001-8791(02)00030-1

Bakker, A. B., Demerouti, E., \& Sanz-Vergel, A. I. (2014). Burnout and work engagement: The 
JD-R approach. Annual Review of Organizational Psychology and Organizational Behavior, 1(1), 389-411. doi: 10.1146/annurev-orgpsych-031413-091235

Bakker, A., Demerouti, E., \& Schaufeli, W. (2003). Dual processes at work in a call centre: An application of the job demands-resources model. European Journal of Work and Organizational Psychology, 12, 393-417. 10.1080/13594320344000165

Bakker, A. B., Hakanen, J. J., Demerouti, E., \& Xanthopoulou, D. (2007). Job resources boost work engagement, particularly when job demands are high. Journal of Educational Psychology, 99(2), 274. doi: 10.1037/0022-0663.99.2.274

van Beek, I., Taris, T. W., \& Schaufeli, W. B. (2011). Workaholic and work engaged employees: Dead ringers or worlds apart? Journal of Occupational Health Psychology, 16(4), 468. doi: $10.1037 / \mathrm{a} 0024392$.

Bruk-Lee, V., \& Spector, P. E. (2006). The social stressors-counterproductive work behaviors link: Are conflicts with supervisors and coworkers the same? Journal of Occupational Health Psychology, 11(2), 145. doi: 10.1037/1076-8998.11.2.145

Celeux, G., \& Soromenho, G. (1996). An entropy criterion for assessing the number of clusters in a mixture model. Journal of Classification, 13, 195-212. doi: 10.1007/bf01246098

Cerit, Y. (2009). The effects of servant leadership behaviours of school principals on teachers' job satisfaction. Educational Management Administration \& Leadership, 37(5), 600-623. doi: $10.1177 / 1741143209339650$

Demerouti, E., Bakker, A. B., Nachreiner, F., \& Schaufeli, W. B. (2001). The job demandsresources model of burnout. Journal of Applied psychology, 86(3), 499. doi: $10.1037 / / 0021-9010.86 .3 .499$

Demerouti, E., Mostert, K., \& Bakker, A. B. (2010). Burnout and work engagement: a thorough 
investigation of the independency of both constructs. Journal of Occupational Health Psychology, 15(3), 209. doi: 10.1037/a0019408, hdl.handle.net/1765/63878

Van Dierendonck, D., \& Nuijten, I. (2011). The servant leadership survey: Development and validation of a multidimensional measure. Journal of business and psychology, 26, 249267. doi: 10.1007/s 10869-010-9194-1

González-Romá, V., Schaufeli, W. B., Bakker, A. B., \& Lloret, S. (2006). Burnout and work engagement: Independent factors or opposite poles? Journal of Vocational Behavior, 68(1), 165-174. doi: 10.1016/j.jvb.2005.01.003

Hahn, S. E. (2000). The effects of locus of control on daily exposure, coping and reactivity to work interpersonal stressors:: a diary study. Personality and Individual Differences, 29(4), 729-748. doi: 10.1016/S0191-8869(99)00228-7

Hakanen, J. J., Ropponen, A., Schaufeli, W. B., \& De Witte, H. (2019). Who is Engaged at Work?: A Large-Scale Study in 30 European Countries. Journal of Occupational and Environmental Medicine, 61(5), 373-381.doi: 10.1097/JOM.0000000000001528

Hakanen, J. J., Bakker, A. B., \& Schaufeli, W. B. (2006). Burnout and work engagement among teachers. Journal of School Psychology, 43(6), 495-513. doi: 10.1016/j.jsp.2005.11.001

Innanen, H., Tolvanen, A., \& Salmela-Aro, K. (2014). Burnout, work engagement and workaholism among highly educated employees: Profiles, antecedents and outcomes. Burnout Research, 1, 38-49. doi: 10.1016/j.burn.2014.04.001

de Jonge, J., van Vegchel, N., Shimazu, A., Schaufeli, W., \& Dormann, C. (2010). A longitudinal test of the demand-control model using specific job demands and specific job control. International Journal of Behavioral Medicine, 17(2), 125-133. doi: $10.1007 / \mathrm{s} 12529-010-9081-1$ 
Joseph, E. E., \& Winston, B. E. (2005). A correlation of servant leadership, leader trust, and organizational trust. Leadership \& Organization Development Journal, 26(1), 6-22. doi: $10.1108 / 01437730510575552$

Leiter, M. P., \& Maslach, C. (2016). Latent burnout profiles: A new approach to understanding the burnout experience. Burnout Research, 3(4), 89-100. doi: 10.1016/j.burn.2016.09.001

Luthans, F., \& Avolio, B. J. (2003). Authentic leadership: A positive developmental approach. In K. S. Cameron, J. E. Dutton, \& R. E. Quinn (Eds.), Positive organizational scholarship (pp. 241-261). San Francisco: Barrett-Koehler.

Knisely, M. R., \& Draucker, C. B. (2016). Using a person-oriented approach in nursing research. Western Journal of Nursing Research, 38(4), 508-520. doi: $10.1177 / 0193945915602856$

Maxwell, S. E., Lau, M. Y., \& Howard, G. S. (2015). Is psychology suffering from a replication crisis? What does "failure to replicate" really mean?. American Psychologist, 70(6), 487. doi: $10.1037 / \mathrm{a} 0039400$.

Moeller, J., Ivcevic, Z., White, A. E., Menges, J. I., \& Brackett, M. A. (2018). Highly engaged but burned out: intra-individual profiles in the US workforce. Career Development International, 23, 86-105. doi: 10.1108/CDI-12-2016-0215

Muthén, L., \& Muthén, B. O. (1998-2020). Mplus. User's guide. Los Angeles, CA: Muthén \& Muthén.

Mäkikangas, A., Feldt, T., Kinnunen, U., \& Tolvanen, A. (2012). Do low burnout and high work engagement always go hand in hand? Investigation of the energy and identification dimensions in longitudinal data. Anxiety, Stress \& Coping, 25(1), 93-116. doi: $10.1080 / 10615806.2011 .565411$ 
Mäkikangas, A., Hyvönen, K., \& Feldt, T. (2017). The energy and identification continua of burnout and work engagement: Developmental profiles over eight years. Burnout Research, 5, 44-54. doi: 10.1016/j.burn.2017.04.002

Mäkikangas, A., \& Kinnunen, U. (2016). The person-oriented approach to burnout: A systematic review. Burnout Research, 3(1), 11-23. doi: 10.1016/j.burn.2015.12.002

Mäkikangas, A., Kinnunen, U., Feldt, T., \& Schaufeli, W. (2016). The longitudinal development of employee well-being: A systematic review. Work \& Stress, 30(1), 46-70. doi: $10.1080 / 02678373.2015 .1126870$

Mäkikangas, A., Kinnunen, S., Rantanen, J., Mauno, S., Tolvanen, A., \& Bakker, A. B. (2014). Association between vigor and exhaustion during the workweek: A person-centered approach to daily assessments. Anxiety, Stress, \& Coping, 27(5), 555-575. doi: $10.1080 / 10615806.2013 .860968$

Näätänen, P., Aro, A., Matthiesen, S., \& Salmela-Aro, K. (2003). Bergen Burnout Indicator 15. Helsinki: Edita.

Pasca, R., \& Wagner, S. L. (2011). Occupational stress in the multicultural workplace. Journal of Immigrant and Minority Health, 13(4), 697-705. doi: 10.1007/s10903-011-9457-6

Pasca, R., \& Wagner, S. L. (2012). Occupational stress, mental health and satisfaction in the Canadian multicultural workplace. Social Indicators Research, 109(3), 377-393. doi: 10.1007/s10903-011-9457-6

Peeters, M. C., Montgomery, A. J., Bakker, A. B., \& Schaufeli, W. B. (2005). Balancing work and home: how job and home demands are related to burnout. International Journal of Stress Management, 12(1), 43. doi: 10.1037/1072-5245.12.1.43

Pinto, J. K., Dawood, S., \& Pinto, M. B. (2014). Project management and burnout: Implications 
of the Demand-Control-Support model on project-based work. International Journal of Project Management, 32(4), 578-589. doi: 10.1016/j.ijproman.2013.09.003

Pyhältö, K., Pietarinen, J., \& Salmela-Aro, K. (2011). Teacher-working-environment fit as a framework for burnout experienced by Finnish teachers. Teaching and Teacher Education, 27(7), 1101-1110. doi: 10.1016/j.tate.2011.05.006

Rozkwitalska, M., \& Basinska, B. A. (2015). Job satisfaction in the multicultural environment of multinational corporations: Using the positive approach to empower organizational success. Baltic Journal of Management, 10(3), 366-387. doi: 10.1108/BJM-06-20140106

Russell, R. F., \& Gregory Stone, A. (2002). A review of servant leadership attributes: Developing a practical model. Leadership \& Organization Development Journal, 23(3), 145-157. doi: 10.1108/01437730210424

Salmela-Aro, K., Hietajärvi, L., \& Lonka, K. (2019). Work Burnout and Engagement Profiles Among Teachers. Frontiers in Psychology, 10, 2254. doi: 10.3389/fpsyg.2019.02254

Salmela-Aro, K., Kiuru, N., Leskinen, E., \& Nurmi, J. E. (2009). School burnout inventory (SBI) reliability and validity. European Journal of Psychological Assessment, 25(1), 48-57. doi: $10.1027 / 1015-5759.25 .1 .48$

Salmela-Aro, K., Näätänen, P., \& Nurmi, J. E. (2004). The role of work-related personal projects during two burnout interventions: a longitudinal study. Work \& Stress, 18(3), 208-230. doi: $10.1080 / 02678370412331317480$

Salmela-Aro, K., Rantanen, J., Hyvönen, K., Tilleman, K., \& Feldt, T. (2011). Bergen Burnout 
Inventory: reliability and validity among Finnish and Estonian managers. International Archives of Occupational and Environmental Health, 84(6), 635-645. doi:

$10.1007 / \mathrm{s} 00420-010-0594-3$

Salmela-Aro, K., \& Upadyaya, K. (2014). School burnout and engagement in the context of demands-resources model. British Journal of Educational Psychology, 84(1), 137-151. doi: $10.1111 /$ bjep. 12018

Salmela-Aro, K., \& Upadyaya, K. (2018). Role of demands-resources in work engagement and burnout in different career stages. Journal of Vocational Behavior, 108, 190-200. doi: 10.1016/j.jvb.2018.08.002

Schaufeli, W. B. (2017). Applying the job demands-resources model. Organizational Dynamics, 2(46), 120-132. doi: 10.1016/j.orgdyn.2017.04.008

Schaufeli, W. B., Salanova, M., González-Romá, V., \& Bakker, A. B. (2002). The measurement of engagement and burnout: A two sample confirmatory factor analytic approach. Journal of Happiness Studies, 3, 71-92. doi: 10.1023/A:1015630930326

Schaufeli, W. B., Taris, T. W., \& Van Rhenen, W. (2008). Workaholism, burnout, and work engagement: three of a kind or three different kinds of employee well-being? Applied Psychology, 57, 173-203. doi: 10.1111/j.1464-0597.2007.00285.x

Scholz, U., Doña, B. G., Sud, S., \& Schwarzer, R. (2002). Is general self-efficacy a universal construct? Psychometric findings from 25 countries. European Journal of Psychological Assessment, 18(3), 242. doi: 10.1027//1015-5759.18.3.242

Seppälä, P., Mauno, S., Feldt, T., Hakanen, J., Kinnunen, U., Tolvanen, A., \& Schaufeli, W. (2009). The construct validity of the Utrecht Work Engagement Scale: Multisample and longitudinal evidence. Journal of Happiness Studies, 10(4), 459. doi: 


\section{$10.1007 / \mathrm{s} 10902-008-9100-\mathrm{y}$}

Shrout, P. E., \& Rodgers, J. L. (2018). Psychology, science, and knowledge construction: Broadening perspectives from the replication crisis. Annual Review of Psychology, 69, 487-510. doi: 10.1146/annurev-psych-122216-011845

Smith, B.W., Dalen, J., Wiggins, K. Tooley, E., Christopher, P. \& Bernard, J. (2008). The Brief Resilience Scale: Assessing the Ability to Bounce Back. International Journal of Behavioral Medicine, 15, 194-200. doi: 10.1007/s10869-010-9194-1

Timms, C., Brough, P., \& Graham, D. (2012). Burnt-out but engaged: the co-existence of psychological burnout and engagement. Journal of Educational Administration, 50(3), 327-345. doi: $10.1108 / 09578231211223338$

Upadyaya, K., \& Salmela-Aro, K. (2013). Development of school engagement in association with academic success and well-being in varying social contexts: A review of empirical research. European Psychologist, 18(2), 136. doi: 10.1027/1016-9040/a000143

Upadyaya, K., Vartiainen, M., \& Salmela-Aro, K. (2016). From job demands and resources to work engagement, burnout, life satisfaction, depressive symptoms, and occupational health. Burnout Research, 3(4), 101-108. doi: 10.1016/j.burn.2016.10.001

Van Yperen, N. W., \& Hagedoorn, M. (2003). Do high job demands increase intrinsic motivation or fatigue or both? The role of job control and job social support. Academy of Management Journal, 46(3), 339-348. doi: 10.5465/30040627

Woo, S. E., Jebb, A. T., Tay, L., \& Parrigon, S. (2018). Putting the "person" in the center: Review and synthesis of person-centered approaches and methods in organizational science. Organizational Research Methods, 1, 1-32. doi: 10.1177/1094428117752467

Xanthopoulou, D., Bakker, A. B., Demerouti, E., \& Schaufeli, W. B. (2009). Reciprocal 
relationships between job resources, personal resources, and work engagement. Journal of Vocational Behavior, 74(3), 235-244. doi: 10.1016/j.jvb.2008.11.003 
Table 1

Pearson Correlation Coefficients between the Burnout Dimensions, Engagement, and Their Antecedents.

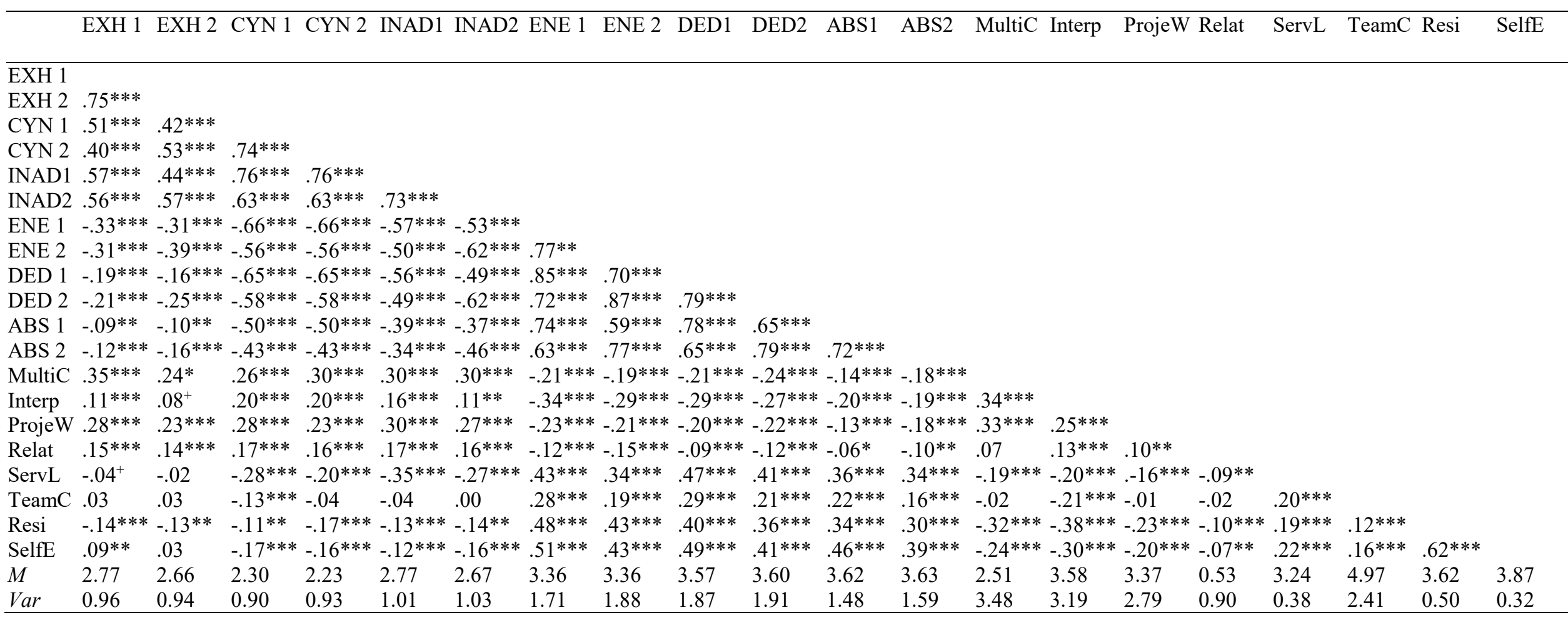

Note. ${ }^{* * *} p<.001 ;{ }^{* *} p<.01 ;{ }^{*} p<.05 ;{ }^{+} \mathrm{p}<.10 ; \mathrm{EXH}=$ exhaustion; $\mathrm{CYN}=$ cynicism; INAD = inadequacy; $\mathrm{ENe}=$ energy; DED = dedication; $\mathrm{ABS}=$ absorption; MultiC $=$ multicultural demands; Interp $=$ interpersonal demands; ProjeW $=$ project work demands; Relat = relationship demands; ServL $=$ servant leadership; TeamC $=$ team climate; Resi $=$ resilience; SelfE $=$ self-efficacy 
Running head: JOB BURNOUT AND ENGAGEMENT PROFILES

Table 2

Fit Indices for the Compared Mixture Models.

\begin{tabular}{llllllllll}
\hline $\begin{array}{l}\text { Number } \\
\text { of } \\
\text { classes }\end{array}$ & $B I C$ & $\Delta B I C$ & $A I C$ & Entropy & $L M R$ & VLMR & $\begin{array}{l}\text { Difference } \\
\text { in the } \\
\text { number of } \\
\text { parameters }\end{array}$ & $\begin{array}{l}p \text { value } \\
\text { Latent class } \\
\text { proportions }(\%)\end{array}$ \\
\hline 1 & 8888.25 & 8783.47 & 8735.10 & & & & & & \\
2 & 8867.01 & 8740.00 & 8681.37 & 0.77 & 0.01 & -4334.55 & 7 & .01 & $84 / 16$ \\
3 & 8884.32 & 8735.08 & 8666.19 & 0.83 & 0.96 & -4275.53 & 7 & .96 & $80 / 17 / 3$ \\
4 & 8895.98 & 8724.50 & 8645.35 & 0.71 & 1.00 & -4216.60 & 7 & 0.99 & $44 / 42 / 12 / 2$ \\
5 & 8918.05 & 8724.35 & 8634.94 & 0.74 & 0.99 & -4169.04 & 7 & 0.99 & $42 / 40 / 13 / 3 / 2$ \\
\hline
\end{tabular}


Running head: JOB BURNOUT AND ENGAGEMENT PROFILES

Table 3

Estimated Log Odds for the Antecedents Predicting the

Latent Group Membership.

\begin{tabular}{|c|c|}
\hline & $\begin{array}{l}\text { High engagement vs. } \\
\text { Increasing burnout } \\
\beta\end{array}$ \\
\hline \multicolumn{2}{|l|}{ Work demands } \\
\hline Multicultural demands & $-.26 * *$ \\
\hline Interpersonal demands & $-.34 * * *$ \\
\hline Project work demands & $-.21 * *$ \\
\hline \multicolumn{2}{|l|}{ Personal demands } \\
\hline Relationship demands & $-.27 * *$ \\
\hline \multicolumn{2}{|l|}{ Work resources } \\
\hline Servant leadership & $.61 * * *$ \\
\hline Team climate & .11 \\
\hline \multicolumn{2}{|l|}{ Personal resources } \\
\hline Resilience & $.90 * * *$ \\
\hline Self-Efficacy & $1.00 * * *$ \\
\hline
\end{tabular}

Note. ${ }^{* * *} p<.001 ;{ }^{* *} p<.01 ;{ }^{*} p<.05$

Note. Increasing burnout group served as the reference group. 